V. P. Neganova

Doctor of Economics, Professor, Institute of Economics, Ural Branch of the Russian Academy of Sciences

A. A. Shemetev

Institute of Economics, Ural Branch of the Russian Academy of Sciences

\title{
MATRIX SUITES APPLYING WHEN MAKING THE COMMERCIAL-COMPANY-
} ACTIVITY-AND-FINANCIAL-RISKS-EXPRESS-DIAGNOSTICS

The paper describes an original method and the method's applying specific features. The method's purpose is providing the commercial-company-activity-and-financial-risks-express-diagnostics. The specific feature of the method is a potential ability for the usage when the financial statements' optimiza- 
tion transformations are potentially being applied. The method can evaluate the business-system financial statement through the prism of these optimization transformations and other factor that can prevent from the business-system-information-field-apperception. The method satisfies the multiple primary conditional equations: apperceptional, asymptotical and simplificational functions. The functions are put into the basis of the model's creation analysis and calculations. This method applying lets to analyze the commercial company activity with minimum iterations condition. The method lets also to analyze the commercial company in the specific Russian conditions.

Keywords: matrix analysis; express-diagnostics; financial risk; commercial company activity; Russian conditions optimization transformations evaluating

More and more attention is being paid to the maximally economical (from the asymptotical analysis functions) methods and models in the economics impermanency conditions. These methods and models should be capable for the company-financial-and-risks-activity-diagnostics in the current market conditions. An important gradational limitation border is a potential apperception functional scantiness when applying the data proceeding in conditions of the data insufficiency. The apperceptional and asymptotical limitation creates a limitation conditions multiple function that in its turn establishes certain borders one can create an analysis method in.

Together with this, another function persists: the simplification function. This function is being dictated by the potential and real users who will apply the selected method for the analysis in primary-data-insufficiency-conditions. The expressdiagnostics methods will provide the minimized iterations quantity during the asymptotical analysis in this case. That creates the third limitation line when one creates the methodic suites.

The most profound interest should be paid to the matrix functions applying, taking into an account the above mentioned limitations. Such functions can be applicable for the financial and simultaneously for the risks analysis in the primary-data-insufficiencyconditions. The express-diagnostics methods will also provide the minimized iterations quantity during the asymptotical analysis in this case.

During the complex researches the matrix-express-analysis-method is created. The method can evaluate the commercial company financial stability and risks in the modern market conditions. The method lets to minimize the iterations quantity during the functions' asymptotical analysis. The above mentioned, in its turn, maximally simplifies the calculations when applying the method. The apperceptional function of the model is maximized, that can be very useful for the experts work simplification.
Together with this, the method uses the primary-limited-data-volume of a selected company's activity: for the method using only the financial and income statements are sufficient (\#1\&\#2 OKUD forms in the Russian accountings), including the case when the financial statement optimization transformations applied, for instance, for the tax base minimization or the company's internal activity nontransparency veiling. The business-system's information field distortion for the primary set apperception field refraction in time \& space in the social hronotophy is understood as the nontransparency veiling.

The basic matrix has the next schematic appearance:

$$
\left\langle\begin{array}{lll}
1 & 2 & 3 \\
4 & 5 & 6 \\
7 & 8 & 9
\end{array}\right\rangle
$$

Where: $1,2,3,4,5,6,7,8,9$ - are the conditional names for the used ratios;

Number 1, 2, 3 ratios mean the accepted in the model financial circle indicators;

Number 4, 5, 6 ratios mean the accepted in the model operational and marketing circle indicators;

Number 7, 8, 9 ratios mean the accepted in the model investments circle indicators.

The 42-years-lasted Ghent's university's research's conceptual principle [2] is accepted as the basic theory during the model's creation. According the principle, the above mentioned three cycles influence upon the company's steadiness to an important risk - the risk of bankruptcy. The principle settles the next turn of influence. Financial cycle is the most important in the risks counter-actions. In its fault case the company's insolvency can become obvious after one reporting period (1 year). The operational cycle influences upon the company's production. That is why this cycle can cause the company's income receiving normal process fault, and, therefore, it can influence the financial cycle 
during one reporting period. It, in its turn of events chain, can cause the company's insolvency during the next one reporting period. The investment cycle influences upon the operational cycle self-reproduction process. The investment cycle fault can cause the chain-reaction spreading to the operational cycle during one reporting period with the outgoing consequences.

The terms-of-the-crisis-imperatives are not taken into account in the recent research borders, because such terms are rather a disputable argument. The crisis dynamics cyclical possibility theory of the crisis dynamics spreading is accepted as the events development potential basic scenario. It is put into the common and also into the discriminate-asymptotic matrix. The matrix is represented further in the paper.

Together with the ratios building horizontal dependence, there persists also the indication ratios vertical dependence in the matrix. The 1, 4, 7 indicators in the matrix mean the short-term potential crisis indicators in a company's activity. The 2, 5, 8 indicators in the matrix mean the average-term potential crisis indicators in a company's activity. The 3, 6, 9 indicators in the matrix mean the long-term potential crisis indicators in a company's activity.

The diagonal dependences 1, 5, 9 and 7, 5, 3 in the matrix characterize the company's activity express cut-off in all the three periods in all the cycles (investments, operational, marketing and financial). The diagonal dependence 1, 5, 7 characterizes an express-analysis for mostly crisis companies with financial cycle faults. The 7, 5, 3 diagonal dependence characterizes an express-analysis for mostly normally functioning companies in the recent market conditions with the potential and real faults in the investments cycle. The indicators that used in the model are described further in the paper.

The following was established next: the minimal number of iterations is achieved when using the simple financial rations in the model, the ratios that disclose simple dependences the matrix system was adopted for usage with. Thus is achieved the minimal and at the same time optimal number of iterations in data gathering simplification and the model usage and also in the common apperception during the model usage. It was disclosed by the asymptotical iterations analysis with taking into account the above mentioned simplification and apperception functions. Taking into account the mentioned above, the numerical indicators for the express-diagnostics purposes are represented in the financial ratios form, the financial ratios that disclose the company's financial statement and risks in fact.

The ratio 1 is described by the next inequality:

$$
\frac{W A C C(3 \mathrm{~K})}{\mathrm{Ч \Pi}} \geq 1
$$

Where: ЧП — is the sum of net profit that can be taking from even the optimized income statement (from \#2 OKUD).

WACC $(3 \mathrm{~K})$ - is calculated in monetary equivalent of the weighted average cost of borrowed capital; it can be calculated using the next equation:

$$
W A C C(3 \mathrm{~K})=d 3 \mathrm{~K} \times k \% \times(1-T),
$$

Where: $\mathrm{d} 3 \mathrm{~K}-$ is a borrowed capital stake in the company; $\mathrm{k} \%$ - is an average $\%$ of borrowed capital cost of attraction to a company; $\mathrm{T}$ - is a tax regulator that should be calculated from the income tax rate with the accountings-law-restrictionstaking-into-account. It is disclosed and explained in much more details about the $\mathrm{T}$ rate and other WACC elements calculations in [5, p. 109]. 1 - in the equation (2) is not a some-law-relative-indicator. This number testimonies about the overcoming or non-overcoming of the weighted average cost of borrowed capital upon the net profit sum both calculated in the comparable monetary equivalent.

The inequality (2) realization means the potential financial risk of the business-system financialcycle-fault-in-a-short-term-risk. Together with this, many companies apply the financial statement optimization transformations for the tax optimization purpose that can greatly distort the net profit sum and other related indicators. The simple and asymptotic matrix analysis is used for this problem resolving.

The ratio 2 is described by the next inequality:

$$
\frac{W A C C(3 \mathrm{~K})}{E B I T} \geq 1,
$$

Where: EBIT — earnings before interests and taxes.

This indicator in the matrix is performed so that the sum of the interests to pay can be taken right from the Russian income statement that is very important in the Russian actuality and reality conditions. The interests normative restrictions accounting is taken into account in the matrix complex analysis. 
The inequality (4) realization means the potential financial risk of the business-system financial-cycle-fault-in-an-average-term-risk.

The ratio 3 is described by the next inequality:

$$
\frac{W A C C(3 К)}{\text { Выр }} \geq 1,
$$

Where:

Выр - is the sum volume of the revenue received during the financial reporting period.

The inequality (5) realization means the potential financial risk of the business-system financial-cycle-fault-in-a-long-term-risk.

The ratio 4 is described by the next inequality:

$$
\frac{N O I\left(\frac{\text { Выр }}{N O I}\right)}{\text { Зап +ДЗ }} \geq 1,
$$

Where: NOI — Net operating income - in the model it is a sum of income before taxes;

Зап - is the sum of all the inventories the company has;

ДЗ - is the total sum of the accounts receivable of all terms (before and after one year) that is in the company's assets.

The inequality (6) realization means the minimized potential financial risk of the business-system operational-and-marketing-cycle-fault-in-ashort-term-risk.

The ratio 5 is described by the next inequality:

$$
\frac{\text { Выр }}{\mathrm{OA}-\mathrm{HДC}+Д Ф В} \geq 1,
$$

Where: OA - is the sum of the company's current (mobile) assets, it is the end sum of the balance sheet II part (\#1 OKUD form);

НДС - VAT sum in the company's assets;

ДФВ - long-term financial holdings sum in \#1 OKUD form

The inequality (7) realization means the minimized potential financial risk of the business-system operational-and-marketing-cycle-fault-in-anaverage-term-risk.

The ratio 6 is described by the next inequality:

$$
\frac{\text { Выр }}{\mathrm{OA}+3 \mathrm{a \Pi}} \geq 1 \text {. }
$$

The inequality (8) realization means the minimized potential financial risk of the business-sys- tem operational-and-marketing-cycle-fault-in-along-term-risk.

The ratio 7 is described by the next inequality:

$$
\frac{\mathrm{OC}_{\mathrm{KOH}}-\mathrm{OC}_{\mathrm{HA \Psi}}}{\mathrm{OC}_{\mathrm{HA \Psi}}} \geq 0,15 \text {, }
$$

Where: $\mathrm{OC}_{\mathrm{KO}}$ - is the property, plant and equipment sum at the end of the reporting period;

$\mathrm{OC}_{\mathrm{HAY}}$ - is the property, plant and equipment sum at the beginning of the reporting period

0,15 - is a calculated from the average-industrial-ratios in the main industries of the economics; it is a ratio that indicates the minimized businesssystem-investment-cycle-development-for-property-plant-and-equipment-renovation

The inequality (9) realization means the minimized potential financial risk of the business-system investment-cycle-fault-in-a-short-term-risk.

The ratio 8 is described by the next inequality:

$$
\frac{W A C C(\mathrm{CK} \%)}{\left(\frac{\mathrm{Ч \Pi}}{\mathrm{CK}}\right)} \geq 1,
$$

Where: CK - is a sum of the owned capital stake; this sum is the end result of the III part of the passive of the balance sheet (\#1 OKUD form);

WACC $(\mathrm{CK} \%)$ - is evaluated in a percentage mean the weighted average cost of the company's owned capital stake; it is an equivalent of the investments return norm.

The source [5] describes the WACC(CK) and WACC $(\mathrm{CK} \%)$ more profound.

The inequality (10) realization means the minimized potential financial risk of the business-system investment-cycle-fault-in-an-average-term-risk.

The ratio 9 is described by the next inequality:

$$
\frac{\mathrm{BБ}_{\mathrm{KOH}}-\mathrm{BБ}_{\mathrm{HAY}}}{\mathrm{BБ}_{\mathrm{HA \Psi}}} \geq 0,15
$$

Where: $\mathrm{BБ}_{\text {кон }}$ - is the total company's balance sheet value at the end of the reporting period;

$\mathrm{BБ}_{\mathrm{HAY}}$ - is the total company's balance sheet value at the beginning of the reporting period.

The inequality (11) realization means the minimized potential financial risk of the business-system investment-cycle-fault-in-a-long-term-risk.

Matrix (1) has the next appearance: 


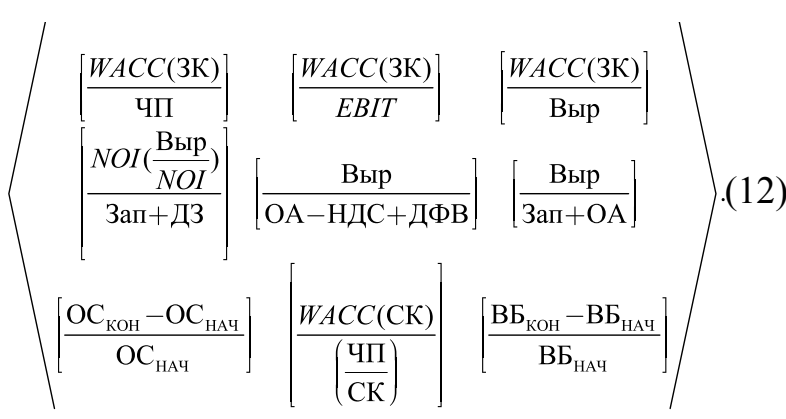

The determinant of such matrix shows the level of the business-system abnormal risk distribution with taking into an account such factor as potential optimization transformations usage in the Russian conditions. The step-by-step algorithm of the matrix determinant calculation with the modern computer technologies usage and without it is described in [5].

The critical matrix indicator is the NOI sum. When NOI is above 0 , the next conclusion is fair.

The matrix determinant deviation from 0.00000 means the abnormal risks distribution.

The matrix determinant meaning below 0 means the forced company's stream activity orientation in priority to the cash flow management problems resolution, production and marketing processes management; together with this, the less and the below from -1 the determinant is, the more effective the practical realization of the stream is taken place into a company. In case when the borrowed capital for a company is cheaper than the owned one, the risks of such company are mostly connected with the investment and marketing cycles risks. The negative development scenario for such company is connected with the slow step-by-step obsolescence of such firm and its production. The catastrophically oriented such firm's development scenario is connected with the company's cash flows interception by the creditors and the other parties.

In case when the borrowed capital for a company is more expensive than the owned one, it testimonies the persistence of the company's financial cycle risk in priority. Such company is forced to manage its cash flows not to let the financial cycle normal functioning interruptions.

When the matrix determinant is above +0.00000 , it means the company has risks connected with the investment cycle. For such company the different levels investments flow management should become the main basis of its functioning.

In case when the critical indicator, the NOI, is primary below 0 , the results interpretation for the abnormal risk distribution is next.
In case when the matrix determinant is above +0.00 one can conclude about a profound risk for a company. It is the risk for the financial, operational and marketing cycles. The worst such company's development variant is the firm's cash flows interception by the creditors and by the third parties.

In case when the matrix determinant is in the interval from minus 1 to 0.00 , it testifies about the management system insufficient efficiency inside a selected company. This insufficiency is obviously visible when one compare such company with the companies that matrix determinant is above minus 1. The lower the matrix determinant results from minus 1 , the higher the management potential in such company is.

Together with this, it is useful to apply the created from the asymptotical analysis method matrix. It is set, that the apperception optimization is obvious in the logarithmical matrix analysis. According to the logarithm's main property, any logarithm in the end result can be reduced to the natural logarithm. Such reduction is widely applied in the asymptotic analysis. In such case the matrix system (12) has the next appearance:

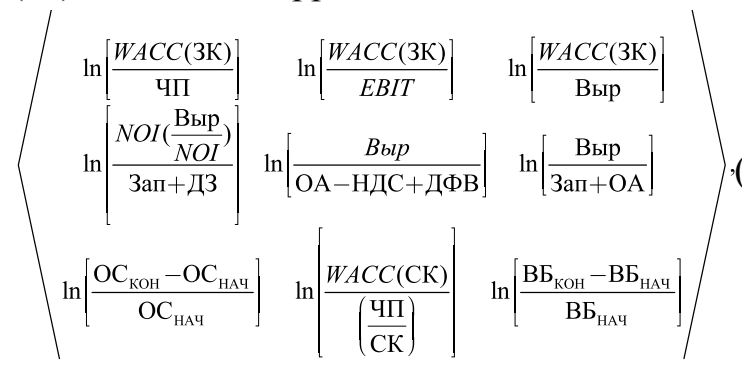

Where: $\ln$ - is a natural logarithm from a ratio.

The basis of this logarithm is a constant $\mathrm{e}$ $(2,7182828 \ldots .$.$) . This basis is taken because of the$ main logarithm's property in the asymptotic analysis conditions. This logarithm has certain limitation functions. These limitation functions are caused by logarithmical function region of acceptability.

Such matrix determinant existence in its essence testifies about the positive trends in the company's activity during a selected period. It is caused by the logaritmical-and-matrix-function-admitted-region. When the determinant exists it is obviously that the net profit and also profit, and NOI is above 0 ; the growth of the company's balance sheet value and also of the company's production base persists (the last point is indicated through the property, plant and equipment dynamics prism); it also testifies the owned capital value is above 0 (less than $1 \%$ of the companies in the Russian reality have the owned capital value below 0 ). 
The matrix (13) determinant existence for a business-system testifies about the effective management organization, notwithstanding on the abnormal risk distribution function persistence or lack (that can be calculated from the matrix (12) determinant estimation). The lower the function value is, the higher is the cumulative company's management's potential; it especially touches the situations when the matrix determinant value is below minus 1 .

En masse, the matrix analysis usage can become a powerful additional instrument for the financialpermanency-business-system-functioning-in-market-conditions-conceptual-verification-problemresolution. The optimization financial statement's transformations are not distorting the end results of the analysis very much. A hard distortion is highly possible when the classical financial analysis is applied with the common means usage. The above mentioned advances the described in the paper matrix analysis method.

The double matrix analysis helps to realize some company's market activity more profoundly. Together with this, the ratios themselves are objects for the analysis. The ratios are subdivided according the company's functioning time priorities and cycles functioning (operational, investment, marketing and financial). Such triple analysis helps in a problem resolution. And the problem is businesssystem-functioning-financial-risks-and-stabilityfinancial-analysis.

The external medium dynamics fluctuation trends today tend to judge about the economics impermanency conditions in the economics. The above mentioned economics statement in fact forces many domestic companies the more and more strengthen the financial statement's optimization transformations usage. It, in its turn, makes the financial and risks analysis classical systems almost inapplicable in the Russian reality conditions. The new mathematical model is in prior created to resolve this scientific-paradigm-problem.

The method is also applicable to be applied by the commercial banks to analyze the credit portfolio elements.

The result apperception is described by the limits functions. It, in its turn, is made for the model end results' apperception simplification conceptual principle following. The limits functions system as the model's end result lets to do the complex deductions about the atomar-business-system's-financialactivity-and-risks by the express-diagnostics and analysis methods.

The matrix analysis system's usage lets to establish the internal-in-depth-processes-essence in the atomar-business-system-borders. It also lets to direct all the forces to the potential and real internal and external medium's instability displays in the time-and-space conditions.

Together with this, the iterations number during the asymptotical analysis lets to judge about a low iterations and calculations number model's costs. It lets the model application as an expressdiagnostic method with the minimal time cost of the model usage. The costs reduction effect during the risks analysis is $72.4 \%$. The model effectiveness calculated by a particular method applying by means of comparing with the classical theory of financial stability is $284.2 \%$. The total cumulative method effect is $181.7 \%$ in the non-multiplicative-interpretation-form.

\section{References}

1. Chereshnev V. A. (Ed.), Tatarkin A. I. (Ed.) (2010). Social-economics risks: reasons diagnostics and prognosis neutralization scenarios Ekaterinburg: UrB of RAS Institute of Economics.

2. Ooghe H., Balcaen S. (2002). Are failure prediction models transferable from one country to another? An empirical study using Belgian financial statements. Ghent: Ghent University.

3. Neganova V. P. (2000). AIC companies marketing strategies forming and development (by the Ural economics district example): Dr.Sc. Thesis: 08.00.05. Ekaterinburg.

4. Neganova I. S. (2006). Core competences based companies competitive ability increasing: Ph.D. Thesis: 08.00.05: Ekaterinburg.

5. Shemetev A. A. (2009). Complex financial analysis and bankruptcy prognosing and also financial management-marketing self-taught book. Ekaterinburg: Polygraphist.

\section{Information about the authors}

Neganova Valentina Petrovna (Ekaterinburg) - Doctor of Economics, Professor, Head of the agricultural and food policy division at the Institute of Economics, Ural Branch of the Russian Academy of Sciences (620014, Ekaterinburg, Moskovskaya St. 29, e-mail: agrour@mail.ru).

Shemetev Aleksandr Aleksandrovich (Ekaterinburg) - applicant at the Institute of Economics, Ural Branch of the Russian Academy of Sciences (620014, Ekaterinburg, Moskovskaya St. 29, e-mail: agrour@mail.ru). 